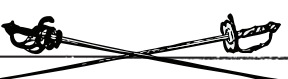

\title{
Isabel Frances Bellows' "A Deadly Tend" and the cultural confines of the Duel and the Police
}

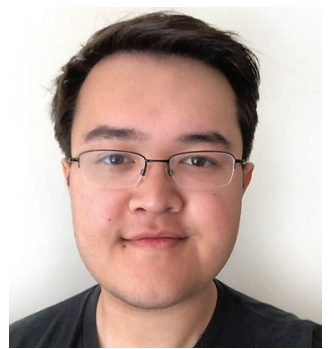

\section{BY HUGH HICKMAN}

STUDENT ESSAY

Golden Age of Children's

Literature Course
From Aesop's Fables to Peter and Wendy, children's literature combines the innocent, exuberant state of childhood with the grit and grime of reality, often introducing and imprinting upon youth grave concepts beyond their grasp such as crime and death. Isabel Frances Bellows' “A Deadly Feud" is just such an example, appearing during the heyday of the Golden Age of Children's literature in the 9th issue of the 14th volume of St. Nicholas Magazine published in 1887.
B ellows' brief poem details a contentious interaction between a Bumblebee and a Wicked Flea: the Bumblebee lambastes the Flea for his tacit, unsavory ways as they will contribute to his inevitable end behind the bars of the county jail. The Wicked Flea takes offense to the Bumblebee's statement and upon equally insulting the "fat old" creature, challenges him to a duel. Bellows blends discourses on the cultural phenomenon of the duel and the role of the police as authority into a cute, 26-line jingle, accompanied by charming anthropomorphized illustrations of the insects, complete with hats and canes. By analyzing the conception of duels and police forces in "A Deadly Feud" through a historical and cultural lens, this essay reflects on the sentiments and circumstances of late 19th-century America that inform the subject matter of Bellows' poetic work.

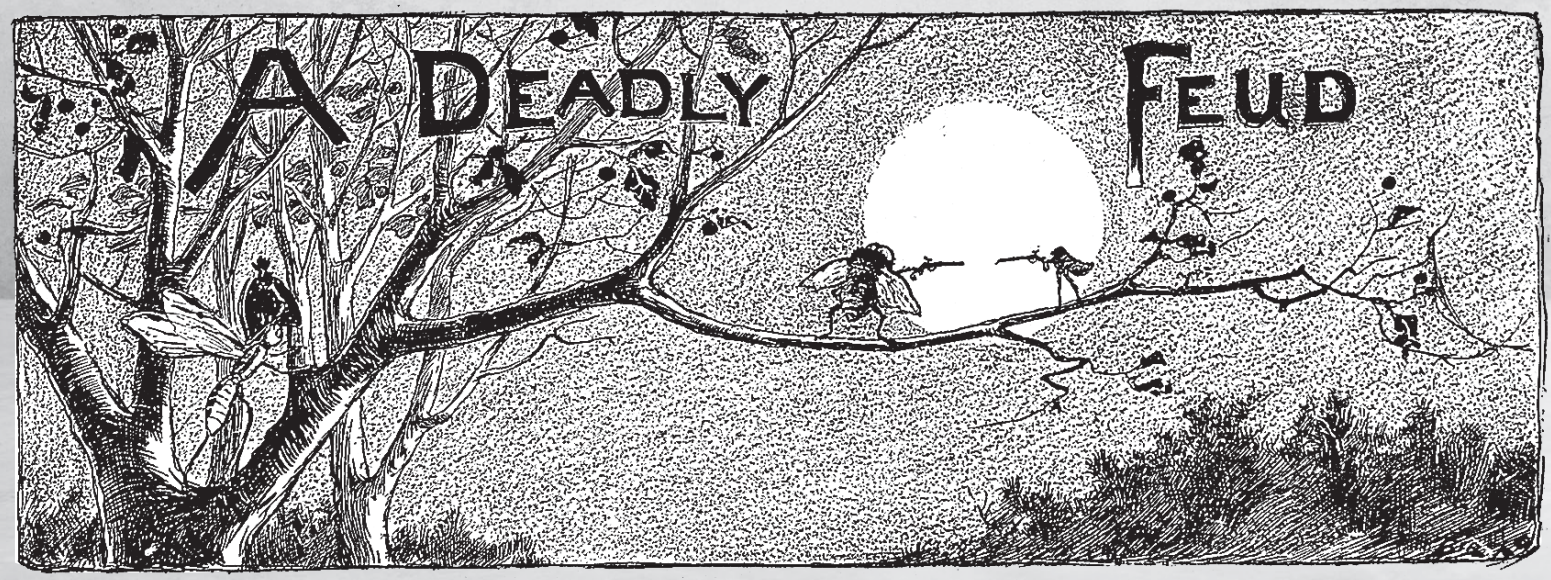


At first glance, the content and the story in Bellows' piece might be considered benign or a trumpery, a rhyme to satisfy children paired with illustrations similar to E. H. Shepherd's in The Wind in the Willows. The plain rhyme schemes of "Gnat" and "hat," "straw" and "law," and "tones" and "bones" are elementary, convivial, and childlike; to the ear, the stanza is plainly enjoyable. On the other hand, the subject matter of the poem deals with decades of violence from police forces in America and the phenomenon of dueling, an honor-based system of justifiable murder. In this modulation and compilation, Bellows' work opens the door for discussing what conveying these two cultural systems of control to children may mean for many who thought they were living in the realm of the Golden Age. By communicating this knowledge about dueling culture and police rule, the implications and ramifications of violence are impressed upon the audience - in this case, upon the malleable minds of American children, who are young enough to be enamored by basic rhymes and talking animals. With characters wielding pistols and whips, arguing amongst themselves, and readily attempting to hurt one another or take another's life, all within regulation of American law, the readers of "A Deadly Feud" may have been made vulnerable, consciously or unconsciously, to the network of violence underlying social institutions.

Isabel Frances Bellows' adorable jingle with its rhyming bugs is an unnoticed, largely forgotten piece of children's literature. Appearing once in a

\section{A. JINGLE.}

By IsABel Frances Bellows.

I.
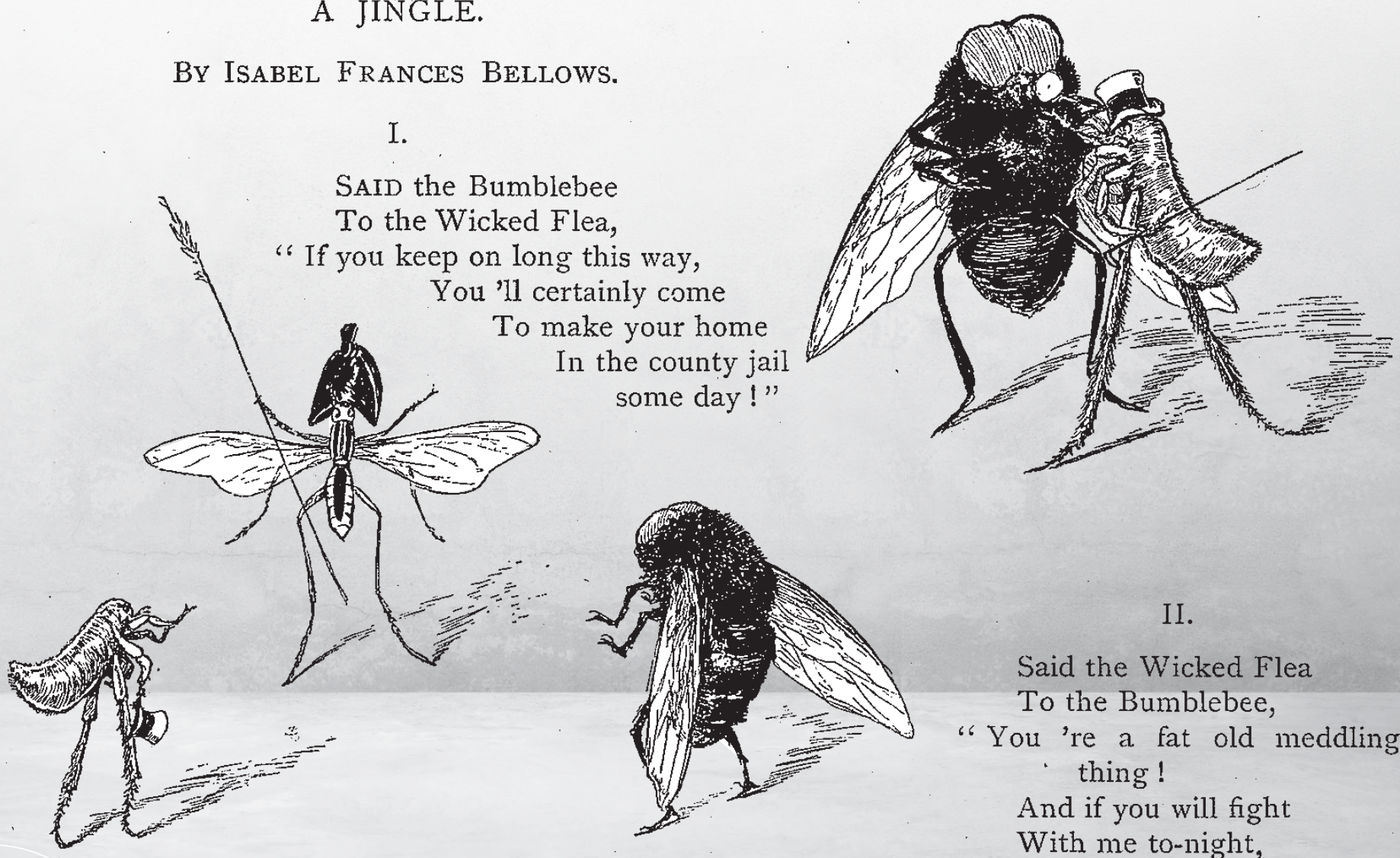

II.

Said the Wicked Flea

To the Bumblebee,

"You 're a fat old meddling thing!

And if you will fight

With me to-night,

Two pistols I will bring." 
magazine in 1887, the work has an enchanting quality to it. At face value, the piece is simple and endearing, but upon delving into the content and the implications of the plot, an entire realm of historical and cultural avenues appears. The Bumblebee and the Wicked Flea engage in a ritual dating back to 16th-century Europe, but display a brand of machismo unique to 19th-century America. The Gnat allows multiple readings of police, rooted in public violence, and their activities and effects on America throughout the country's existence. The two social systems of control interacting teach children about a specifically American cultural reality in which differing classes and personalities meet to fight to the death while the greater physical threat of the police oversee all. In effect, the upper-class Bumblebee, the lower-class Wicked Flea, and the powerful and spiteful Gnat encompass a lawless, violent American reality into which children are brought.

The implications of including the two cultural structures, designed to restrict and restrain individuals' behaviors, in a work for young children beg for further interpretations: psychoanalytical readings for characters and behavior, cultural analyses of social conflict in the era, criticisms of definitions between law and order through the lens of a child. While perhaps not a revolutionary piece of children's literature, "A Deadly Feud"'s 26 brief lines are a goldmine of analyses and entertainment in the overarching Golden Age canon. 澿

111.

Bellows, Isabel Frances “A Deadly Feud." St. Nicholas Magazine, Vol. 14, No. 9, 1887.

When out came the Gnat,

In a shiny hat,

With a whip of barley straw;

And in awful tones

He threatened their bones

With the majesty of the law.

IV.

And the Bumblebee And the Wicked Flea Shivered with fear and dread; And clasping each other Like brother and brother, Precipitately fled!

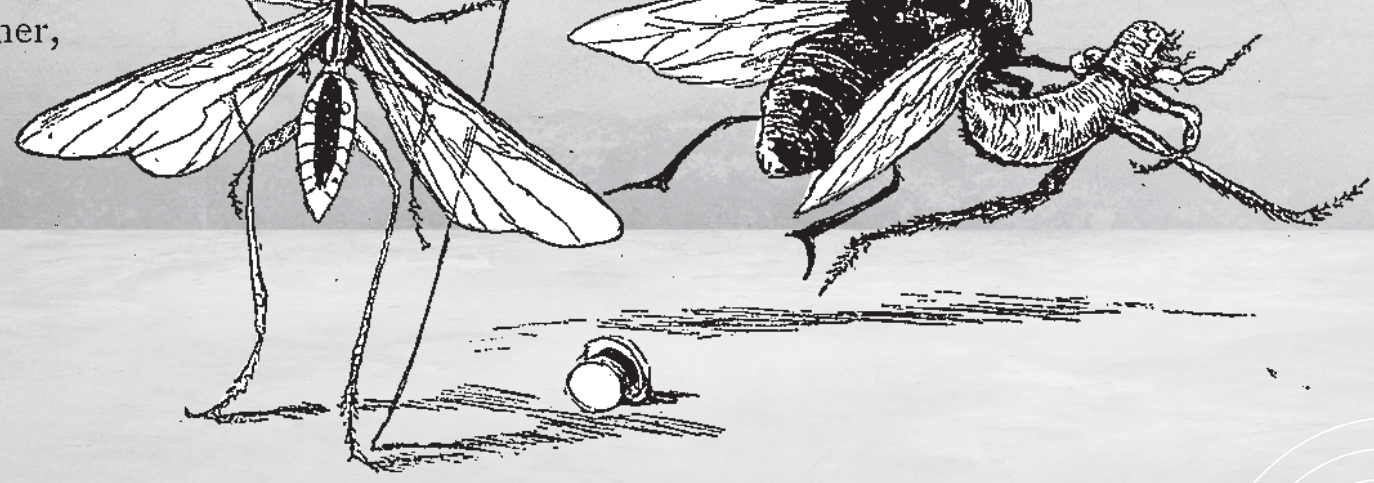

